\title{
Adipokines, insulin resistance, and adiposity as a predictors of metabolic syndrome in child survivors of lymphoma and acute lymphoblastic leukemia of a developing country
}

Lourdes Barbosa-Cortés ${ }^{1,7^{*}}$, Mardia López-Alarcón', Juan Manuel Mejía-Aranguré2, Miguel Klünder-Klünder³, María del Carmen Rodríguez-Zepeda ${ }^{4}$, Hugo Rivera-Márquez ${ }^{5}$, Alan de la Vega-Martínez ${ }^{1}$, Jorge Martin-Trejo ${ }^{4}$, Juan Shum-Luis ${ }^{4}$, Karina Solis-Labastida ${ }^{4}$, Enrique López-Aguilar ${ }^{6}$, Guadalupe Matute-González ${ }^{1}$ and Roberto Bernaldez-Rios

\begin{abstract}
Background: There is a growing body of evidence indicating that pediatric survivors of cancer are at a greater risk of developing metabolic syndrome. This study evaluated some probable predictors of metabolic syndrome (MS), such as leptin and adiponectin concentrations, the leptin/adiponectin ratio, insulin resistance, and adiposity, in a sample of child survivors of lymphoma and leukemia in Mexico City.

Methods: Fifty two children (leukemia $n=26$, lymphoma $n=26$ ), who were within the first 5 years after cessation of therapy, were considered as eligible to participate in the study. Testing included fasting insulin, glucose, adipokines and lipids; body fat mass was measured by DXA. The MS components were analyzed according to tertiles of adipokines, insulin resistance, and adiposity. Comparisons between continuous variables were performed according to the data distribution. The MS components were analyzed according to tertiles of adipokines, insulin resistance, and adiposity. With the purpose of assessing the risk of a present MS diagnosis, odds ratios (OR) with a 95\% confidence interval (95\% IC) were obtained using logistic regression analysis according to the various metabolic markers.

Results: The median children age was 12.1 years, and the interval time from the completion of therapy to study enrollment was 4 years. Among the MS components, the prevalence of HDL-C low was most common (42\%), followed by central obesity (29\%). The HOMA-IR (OR 9.0,95\% Cl 2.0; 41.1), body fat (OR 5.5, 95\% Cl 1.6; 19.3), leptin level (OR 5.7, $95 \% \mathrm{Cl} 1.6 ; 20.2)$ and leptin/adiponectin ratio (OR 9.4, 95\% Cl 2.0; 49.8) in the highest tertile, were predictive factors of developing MS; whereas the lowest tertile of adiponectin was associated with a protective effect but not significant. (Continued on next page)
\end{abstract}

\footnotetext{
* Correspondence: bcmariade@hotmail.com

Deceased

${ }^{1}$ Medical Nutrition Research Unit, 21st Century Pediatric Hospital, National Medical Center, MexicanInstitute of Social Security, México City, México

${ }^{7}$ Medical Nutrition Research Unit, 21st Century Pediatric Hospital, National Medical Center, Mexican Institute of Social Security, Avenida Cuauhtémoc 330 Col. Doctores, México City C.P. 06720, México

Full list of author information is available at the end of the article
} 
(Continued from previous page)

Conclusions: Biomarkers such as HOMA-IR, leptin and leptin/adiponectin are associated with each of the components of the MS and with a heightened risk of suffering MS among children survivors of cancer. Given the close relationship between MS with risk of developing type 2 diabetes and cardiovascular disease, it is imperative to implement prevention measures in this population and especially in developing countries where these pathologies have become the leading cause of death.

Keywords: Childhood cancer survivors, Acute lymphoblastic leukemia and lymphoma, Metabolic syndrome, Adipokines, Insulin resistance, Obesity

\section{Background}

The increase in the survival rates of child cancer patients is accompanied by an increase in the likelihood to develop long-term adverse effects. Specifically, survivors of ALL (Acute lymphoblastic leukemia) and lymphoma are at risk of developing metabolic abnormalities, such as obesity, impaired glucose tolerance, insulin resistance, metabolic syndrome, cardiovascular disease, and diabetes [1-4].

On the other hand, the excess adipose tissue that accompanies obesity alters the release of adipokines, including leptin and adiponectin, which are known to affect insulin sensitivity and vascular functionality, thereby, increasing the risk of MS [5]. In fact, low adiponectin and high leptin concentrations are observed in children with MS and insulin resistance [5, 6]. This imbalance between pro and anti-inflammatory adipokines elicits low degree systemic inflammation, mainly associated with insulin resistance [7, 8]. Even more, both, hypoadiponectinemia and hyperleptinemia are considered to be independent risk factors of the development of type 2 diabetes and cardiovascular diseases [5, 7, 913]. Owing to this fact, its plasmatic concentrations has been proposed as a candidate biomarkers to identify metabolic alterations including those of MS [14]. However, among children survivors of cancer it is not exactly known how and to what extent IR, adiponectin and leptin are associated with each of the components of MS.

Therefore the aim of this study was to evaluate some probable predictors of MS, such as leptin and adiponectin concentrations, the leptin/adiponectin ratio, insulin resistance, and adiposity, in a sample of child survivorsof ALL and lymphoma. To exclude random effects, these factors were re-analyzed after 6 months.

\section{Methods}

\section{Subjects}

Children referred to the Pediatric Hospital from the Mexican Institute of Social Security (IMSS) in Mexico City who previously diagnosed with ALL or lymphoma, and who were within the first 5 years after cessation of therapy, without relapse, no second neoplasm or bone marrow transplants were considered as eligible to participate in the study.
From 61 potential candidates, 52 children met the selection criteria (39 boys and 13 girls); Children who accepted to participate were asked to attend the pediatric hospital on two occasions (baseline examination and 6 months later). This study was approved by the Research and Ethics Committee of the Pediatric Hospital at the Mexican Social Security Institute (2005/3603/071). We obtained written informed consent from parents and informed assent from children.

\section{Procedures}

\section{Anthropometry}

Body weight was measured with an electronic scale (TANITA BWB-700, Tanita Corporation., Tokyo, Japan) with the subjects wearing light-weight clothing. Height was measured to the nearest $0.1 \mathrm{~cm}$ with a wallmounted stadiometer (SECA 222, SECA Corp., Oakland Center, Columbia, MD, USA). Waist circumference was measured at the level of the superior iliac crest to the nearest $0.1 \mathrm{~cm}$, and the values were changed to percentiles according to Fernandez [15]. Body mass index (BMI) and BMI percentiles for age and sex were calculated according to the Center of Disease Control (CDC) normative curves using the computer software Epi-Info (Obesity was defined conventionally as $\geq 95^{\text {th }}$ percentile, overweight as $85^{\text {th }}$ to $94^{\text {th }}$ percentile, and underweight as $<5^{\text {th }}$ percentile [16]. Pubertal stage was determined on the basis of the children's self-assessment by using Tanner's standard photographs for pubic hair and genital development. We did not measure testicular size in the children [17].

\section{Body composition}

Body fat percentage (BFP) was determined by dualenergy X-ray absorptiometry (DXA) using a GE Lunar Prodigy Advance scanner (software version 9.0; GE Medical Systems, Madison, WI, USA). The machine was operated by only one technician.

\section{Metabolic syndrome definition (MS)}

Metabolic syndrome was defined in accordance with the guidelines of the International Diabetes Federation (IDF) [18], with the exception of the cutoff point for blood 
pressure, which was obtained from the National High Blood Pressure Education Program Working Group on high blood pressure in children and adolescents [19]. The rationale is that the cutoff point for blood pressure used by the IDF does not properly represent the effects of age, sex, and stature of children and adolescents. If the IDF criterion is used for blood pressure, the prevalence of high blood pressure would be underestimated because very few children exceed these values. Therefore, children with metabolic syndrome were those with

Table 1 Metabolic characteristics of child survivors of acute lymphoblastic leukemia and lymphoma according to MS

\begin{tabular}{|c|c|c|c|c|c|c|c|c|c|c|}
\hline \multirow[t]{2}{*}{ Variables } & \multicolumn{6}{|c|}{ Firts Assessesment } & \multicolumn{4}{|c|}{ After 6 months } \\
\hline & \multicolumn{2}{|l|}{$\overline{\text { All }}$} & \multicolumn{2}{|c|}{ No MS } & \multicolumn{2}{|l|}{ MS } & \multicolumn{2}{|c|}{ No MS } & \multicolumn{2}{|l|}{ MS } \\
\hline$n$ & 52 & & 45 & & 7 & & 42 & & 10 & \\
\hline $\operatorname{Sex}(M) n(\%)$ & 39 & 75 & 33 & 73 & 6 & 86 & 31 & 74 & 8 & 80 \\
\hline Current age $(Y)^{a}$ & 12.1 & $(7.1,17.0)$ & 12.2 & $(7.1,17.0)$ & 11.1 & $(7.1,17.1)$ & 12.1 & $(7.1,17.0)$ & 11.6 & $(7.1,17.1)$ \\
\hline Age at cancer diagnosis $(Y)^{a}$ & 5.3 & $(1.0,13)$ & 6 & $(0.8,13.0)$ & 4 & $(2,11.1)$ & 6.1 & $(2.1,13.0)$ & 4.1 & $(0.08,12.1)$ \\
\hline Time since completion of therapy $(Y)^{a}$ & 4 & $(2,5)$ & 4 & $(2,5)$ & 4 & $(2,5)$ & 4 & $(2,5)$ & 4 & $(2,5)$ \\
\hline \multicolumn{11}{|l|}{ Diagnosis ( $n \%)$} \\
\hline ALL & 26 & 50 & 22 & 48.9 & 4 & 57.1 & 20 & 47.6 & 6 & 60.0 \\
\hline Lymphoma & 26 & 50 & 23 & 51.1 & 3 & 42.9 & 22 & 52.4 & 4 & 40.0 \\
\hline \multicolumn{11}{|l|}{ Pubertal stage (n \%) } \\
\hline 1 & 33 & 63.5 & 28 & 62.2 & 5 & 71.4 & 18 & 42.9 & 7 & 70.0 \\
\hline$\geq 2$ & 19 & 36.5 & 17 & 37.8 & 2 & 28.6 & 24 & 57.1 & 3 & 30.0 \\
\hline Treatment recived ( $n$ \%) & & & & & & & & & & 0.0 \\
\hline $\mathrm{Ch}$ & 35 & 67.3 & 31 & 68.9 & 4 & 57.1 & 28 & 66.7 & 7 & 70.0 \\
\hline $\mathrm{Ch}+\mathrm{R}$ & 17 & 32.7 & 14 & 31.1 & 3 & 42.9 & 14 & 33.3 & 3 & 30.0 \\
\hline \multicolumn{11}{|l|}{ Nutritional Status (n \%) } \\
\hline Normal & 29 & 55.8 & 28 & 62.2 & 1 & 14.3 & 27 & 64.3 & 0 & 0 \\
\hline Overweight/Obesity & 20 & 38.4 & 14 & 31.1 & 6 & 85.7 & 13 & 31.0 & 10 & 100 \\
\hline Low weight & 3 & 5.8 & 3 & 6.7 & 0 & 0 & 2 & 4.8 & 0 & 0 \\
\hline \multicolumn{11}{|l|}{ MS Components median (min, max) } \\
\hline WC $(\mathrm{cm})$ & \multicolumn{2}{|c|}{$70.5(51.1,105.7)$} & \multicolumn{2}{|c|}{$69.9(51.1,94.8)$} & \multicolumn{2}{|c|}{$78.1(60.4,105.7)^{*}$} & \multicolumn{2}{|c|}{$50(10,100)$} & \multicolumn{2}{|c|}{$90(90,100)^{*}$} \\
\hline $\operatorname{SBP}(p c)$ & \multicolumn{2}{|c|}{$47(2,99)$} & \multicolumn{2}{|c|}{$42.5(2,93)$} & \multicolumn{2}{|c|}{$58(14,99)$} & \multicolumn{2}{|c|}{$16(1,70)$} & \multicolumn{2}{|c|}{$65(19,95)^{*}$} \\
\hline $\mathrm{DBP}(\mathrm{pc})$ & \multicolumn{2}{|c|}{$76(15,99)$} & \multicolumn{2}{|c|}{$75(15,97)$} & \multicolumn{2}{|c|}{$94(19,99)^{*}$} & $54(1$ & 92) & $94(6$ & $99)^{*}$ \\
\hline Triglicerydes (mg/dL) & 96.6 & t, 231) & 85 & 205) & 182 & $7,231)^{*}$ & $80(2$ & 259) & 169 & $4,264)^{*}$ \\
\hline $\mathrm{HDL}-\mathrm{C}(\mathrm{mg} / \mathrm{dL})$ & $40(1$ & 84) & $40(1$ & 84) & $40(1$ & & $45(2$ & 80) & $37(2$ & 68) \\
\hline Glucose (mg/dL) & $89(7$ & 116) & $89(7$ & 116) & $93(7$ & 112) & $93(7$ & 105) & $90(8$ & 115) \\
\hline Others metabolic variables median (mir & $\max )$ & & & & & & & & & \\
\hline Insulin $(\mu \mathrm{U} / \mathrm{mL})$ & 18.9 & $3,55)$ & 18.7 & $3,55)$ & 28.2 & $.5,50)^{*}$ & 22.8 & $4,56.6)$ & 31.5 & $4.5,64)^{*}$ \\
\hline HOMA-IR & 4.3( & $9,13.9)$ & 4.2( & $79,12.7)$ & $7.4(3$ & $13.9)^{*}$ & $5.2(C$ & $8,13.8)$ & $7.3(5$ & $15.4)^{*}$ \\
\hline Adiponectin $(\mu \mathrm{g} / \mathrm{mL})$ & 20.3 & $3,70)$ & 23.4 & $.3,70)$ & 17.5 & $.7,25.4)$ & 20.2 & $64,57.3)$ & 20.3 & $3,37.2)$ \\
\hline Adiponectin per $\mathrm{Kg}$ fat $(\mu \mathrm{g} / \mathrm{mL} / \mathrm{kg})$ & 1.4( & $7,8.0)$ & 1.6( & $7,8.0)$ & 1.0( & $3,3.9)^{*}$ & $1.7(C$ & $6,14.3)$ & 0.90 & $27,3.8)$ \\
\hline Leptin (ng/mL) & 10.1 & 2, 30.9) & 8.0( & , 30.9) & 17.5 & $5,28.6)^{*}$ & 6.5, ( & , 30.9) & $22(9$ & $28.2)^{*}$ \\
\hline Leptin $(\mu \mathrm{g} / \mathrm{mL} / \mathrm{kg})$ & 0.69 & $11,3.9)$ & 0.69 & $11,3.9)$ & 1.0( & $5.7)$ & 0.65 & $11,4.8)$ & $1.0(C$ & $0,4.2)$ \\
\hline Leptin to Adiponectin ratio & 0.44 & $06,11)$ & 0.35 & $.06,11)$ & 0.98 & $59,1.5)^{*}$ & 0.34 & $05,10.4)$ & $1.1(C$ & $1,1.7)^{*}$ \\
\hline Body Fat (\%) & 29.9 & $3,46.7)$ & 27.6 & $3,44.4)$ & 38.3 & $.2,46.7)^{*}$ & 25.5 & $2,45.5)$ & 39.8 & $9.6,49.3)^{*}$ \\
\hline VCAM (ng/mL) & 925 & $5,1730)$ & 930 & $25,1730)$ & 769 & $0,1697)$ & 753 & $77,2045)$ & 683.9 & $514,1081)$ \\
\hline ICAM (ng/mL) & 459 & 4, 1079) & 468 & $54,1079)$ & 412 & $5,685)$ & 456.5 & $184,137)$ & 404 & $99,631)$ \\
\hline
\end{tabular}

${ }^{a}$ Values are median (min, max); Abbreviations: MS Metabolic syndrome, Ch chemotherapy, Ch $+R$ chemotheraphy + radiotherapy, HOMA-IR Homeostatic Model Assessment of Insulin Resistance, VCAM Vascular cell adhesion molecule, ICAM Intercellular adhesion molecule; Comparations were assessed using Mann-Whitney $U$-test due non-normal distribution of the data, and categorized data were analyzed using Fisher's Test; * $p$ value $<0.05$ 
central obesity based on a waist circumference (WC) within $\geq 90^{\text {th }}$ percentile adjusted for age, sex, and Hispanic ethnicity and the presence of two or more of the following features: a) hypertension as diastolic or systolic blood pressure within $\geq 90^{\text {th }}$ percentile for age and sex; b) elevated triglyceride levels of $\geq 150 \mathrm{mg} / \mathrm{dL}$; c) low high-density lipoprotein cholesterol (HDL-c) level of $<40 \mathrm{mg} / \mathrm{dL}$; and d) fasting glucose level of $\geq 100 \mathrm{mg} / \mathrm{L}$.

\section{Analytical methods}

Venous blood samples were collected between 8:00 and 9:00 AM after a 12-h overnight fast. Serum aliquots were separated and frozen at $-80{ }^{\circ} \mathrm{C}$ until biochemical determination. Fasting glucose concentrations were determined by the glucose oxidase method (Beckman Coulter Glucose Analyzer; Beckman Coulter, Brea, CA, USA). Triglycerides, total cholesterol, and HDL-C were measured by the enzymatic colorimetric method (SPIN 120 automatic analyzer Shenzhen, Mindray) with commercially available kits. Leptin and adiponectin levels, vascular cell adhesion molecule (vCAM) and intercellular cell adhesion molecule (iCAM) were determined in duplicate by ELISA (Human Adiponectin, Leptin, vCAM and iCAM ELISA Kits, Millipore, St. Charles, MO, USA), and insulin levels were determined by radioimmunoassay using a commercial kit (Linco Research, St. Charles, MO, USA). Insulin resistance (IR) was determined based on the fasting insulin and glucose concentrations using the Homeostatic Model Assessment of Insulin Resistance [HOMA-IR = (fasting insulin $(\mu \mathrm{U} / \mathrm{ml})$ * fasting glucose $(\mathrm{mmol} / \mathrm{L}) / 22.5)$ [20]. Insulin resistance was defined according to the percentile distribution by age and sex proposed for Mexican children and adolescents [21].

\section{Statistical analysis}

All statistical analyses were performed using SPSS v.18.0 (SPSS Inc., Chicago, IL, USA) and STATA/SE v.11.0 (STATA Corp., College Station, TX, USA). The frequency of MS and each component of MS were obtained, and differences in proportions were assessed by Fisher's exact test. The data were grouped according to the following characteristics: with or without MS features, with or without MS diagnoses, by different cancer treatments, as well as the nutritional status. Anthropometric, metabolic, and inflammatory markers data were tested for normal distribution based in skewness and kurtosis and Shapiro-Wilk test; however, as log transformation did not achieve normal distribution of some of the studied variables such as adiponectin, we show the medians instead of the $\log$ transformations of the non-normally distributes variables. Comparisons between continuous variables were performed with Student's $t$ test or the Mann-Whitney $U$ test according to data distribution. The MS components were analyzed according to tertiles of adipokines, insulin resistance, and adiposity. Differences in metabolic features between the aforementioned tertile categories were obtained using robust linear regression analysis. With the purpose of assessing the risk of a present MS diagnosis, odds ratios (OR) with a 95\% confidence interval (95\% IC) were obtained using logistic regression analysis according to the various metabolic marker tertiles; these data were adjusted by sex, age, treatment, and diagnosis (lymphoma or ALL). The associations were re-evaluated at a 6month follow-up to validate that the findings observed were not due to chance. Additionally, an analysis between the metabolic variables with the changes observed between baseline and 6-month measurements was performed to identify which variables were most influenced by long-term changes. The changes between first evaluation and 6-month measurements were analyzed in tertiles using the middle tertile as a reference value because it was assumed that this tertile did not show changes between the baseline and 6-month measurement. Differences were considered significant at $p<$ 0.05 with all $P$ values based on two-sided tests.

\section{Results}

Demographic and clinical characteristics of participant children are shown in Table 1. At entrance to the study, the median age was 12.1 years, and the interval time from the completion of cancer therapy to study enrollment was 4 years. At enrollment, $38.4 \%$ of children were classified as overweight or obese; after 6 months, the incidence of overweight and obesity increased to $44 \%$. In the same table, the child survivors of leukemia and lymphoma were classified according the presence of MS

Table 2 Prevalence and components of metabolic syndrome in child survivors of acute lymphoblastic leukemia and lymphoma

\begin{tabular}{lll}
\hline MS & First assessment & After 6 months \\
\hline$n$ & 52 & 52 \\
WC $^{\mathrm{a}} \geq 90 \mathrm{pc}^{\mathrm{b}}$ & $15(28.8)$ & $15(28.8)$ \\
Triglycerides $\geq 150 \mathrm{mg} / \mathrm{dL}$ & $9(17.3)$ & $12(23.1)$ \\
$\mathrm{HDL}-C^{c}<40 \mathrm{mg} / \mathrm{dL}$ & $22(42.3)$ & $22(42.3)$ \\
High BP & $14(26.9)$ & $8(15.4)$ \\
Glucose $>100 \mathrm{mg} / \mathrm{dL}$ & $4(7.7)$ & $9(17.3)$ \\
No. of MS criteria & & \\
0 & $14(26.9)$ & $17(32.7)$ \\
1 criteria & $19(36.5)$ & $17(32.7)$ \\
2 criteria & $12(23.1)$ & $8(15.4)$ \\
3 criteria & $6(11.5)$ & $6(11.5)$ \\
4 criteria & $1(1.9)$ & $4(7.7)$ \\
MS & $7(13.5)$ & $10(19.2)$ \\
\hline
\end{tabular}

Values are Number (percentage); Abbreviations: MS Metabolic syndrome, ${ }^{a} W C$ Waist circumference, $p c^{\mathrm{b}}$ Percentile, ${ }^{\mathrm{C}} \mathrm{HDL}-\mathrm{C}$ High density lipoprotein cholesterol, ${ }^{\mathrm{d}}$ Systolic blood pressure $\geq 90 \mathrm{pc}$ or Diastolic blood pressure $\geq 90 \mathrm{pc}$ 
diagnosis at first and 6 months assessments, and as expected, the insulin levels, HOMA-IR index, leptin levels (ng/mL), leptin/adiponectin ratio, and BFP, differed significantly between children with and without MS.

Among the MS components, the prevalence of HDL-C low was most common (42.3\%), followed by central obesity (28.8\%). At 6 months, the number of patients with a diagnosis of MS increased to $19 \%$. Additionally, increasing trends in the number of children with alterations in triglycerides (17.3 to $23.1 \%$ ), and glucose levels
(7.7 to $17.3 \%$ ) and in the number who presented with 4 criteria for the diagnosis of MS (2 to 7.7\%) were observed (Table 2).

The metabolic characteristics of the child survivors of leukemia and lymphoma according to the treatment received and nutritional status are presented in Tables 3 and 4. The results of the analysis of metabolic markers in all the children who received chemotherapy and those who received radiotherapy besides chemotherapy did not significantly differ. Of all the children, $35(67 \%)$ received

Table 3 Metabolic characteristics of child survivors of leukemia and lymphoma according to treatment received at first assessment

\begin{tabular}{|c|c|c|c|c|}
\hline \multirow[b]{3}{*}{ Variables } & \multicolumn{4}{|l|}{ Treatment } \\
\hline & \multicolumn{2}{|c|}{ Chemotherapy $n=32^{a}$} & \multicolumn{2}{|c|}{ Chemotherapy plus radiotherapy $n=17^{b}$} \\
\hline & Normal & Overweigth/Obese & Normal & Overweigth/Obese \\
\hline n: number (\%) & 17 & $15(47)$ & 12 & $5(29)$ \\
\hline $\operatorname{Sex}(M)$ & 12 & 12 & 9 & 4 \\
\hline Current age $(Y)$ & $12.1(8.1,17.0)$ & $12(7.1,17.0)$ & $12.6(7.1,16.1)$ & $12.1(8.0,17.1)$ \\
\hline Age at cancer diagnosis $(Y)$ & $6.0(2.0,13.0)$ & $4.0(2.0,12.1)$ & $6.5(0.08,12.1)$ & $7(1.0,11.1)$ \\
\hline Time since completion of therapy $(Y)$ & $4.0(2.0,5.1)$ & $4.0(2.1,5.1)$ & $3.1(3.0,5.0)$ & $4.0(2.0,5.0)$ \\
\hline Weight (kg) & $46.9(18.1,91.2)$ & & $48.9(26.2,102.9)$ & \\
\hline Height $(\mathrm{cm})$ & $148.4(116.2,178)$ & & $157.9(123,176.1)$ & \\
\hline Diagnosis : ALL/Lymphoma & $11 / 6$ & $9 / 6$ & $4 / 8$ & $1 / 4$ \\
\hline \multicolumn{5}{|l|}{ Pubertal stage } \\
\hline 1 & 9 & $13^{*}$ & 5 & 3 \\
\hline$\geq 2$ & 8 & 2 & 7 & 2 \\
\hline \multicolumn{5}{|l|}{ MS Components } \\
\hline$W C(p c)$ & $25(10,75)$ & $90(50,100)^{*}$ & $50(10,90)$ & $90(75,100)$ \\
\hline $\mathrm{SBP}(p c)$ & $47(3,92)$ & $53(18,93)$ & $17(2,65)$ & $47(20,99)$ \\
\hline $\mathrm{DBP}(p c)$ & $76(15,94)$ & $82(57,99)$ & $75(19,96)$ & $89(39,99)$ \\
\hline Triglicerydes (mg/dL) & $76(34,149)$ & $114(50,231)$ & $72(35,164)$ & $188(148,210)$ \\
\hline $\mathrm{HDL}-\mathrm{C}(\mathrm{mg} / \mathrm{dL})$ & $42(25,84)$ & $39.5(26,78)$ & $42(18,64)$ & $43(18,48)$ \\
\hline Glucose (mg/dL) & $90(75.5,115.7)$ & $91(76,105.7)$ & $86(74,112.5)$ & $93(82,99)$ \\
\hline \multicolumn{5}{|l|}{ Others metabolic variables } \\
\hline Insulin $(\mu \mathrm{U} / \mathrm{mL})$ & $16.3(9.1,38.7)$ & $24.9(14.2,35.3)^{*}$ & $20.5(4.3,50)$ & $36.3(19,55)$ \\
\hline HOMA-IR & $3.6(1.7,9.5)$ & $5.5(2.8,8.2)^{*}$ & $4.3(0.79,13.9)$ & $8.3(4.7,12.7)$ \\
\hline Adiponectin $(\mu \mathrm{g} / \mathrm{mL})$ & $23(1.3,44.3)$ & $22(6.8,70)$ & $19.1(11.7,41.2)$ & $16(1.3,27.6)$ \\
\hline Adiponectin per $\mathrm{Kg}$ fat $(\mu \mathrm{g} / \mathrm{mL} / \mathrm{kg})$ & $1.5(0.39,6.7)$ & $1.2(0.28,4.9)$ & $1.8(0.51,5.1)$ & $0.75(0.7,1.8)$ \\
\hline Leptin $((\mu \mathrm{g} / \mathrm{mL})$ & $4.4(2,13.4)$ & $18.2(9.8,30.9)^{*}$ & $7.4(1.2,19.0)$ & $17.5(13.5,18.5)$ \\
\hline Leptin per $\mathrm{Kg}$ fat $(\mu \mathrm{g} / \mathrm{mL} / \mathrm{kg})$ & $0.49(0.11,3.0)$ & $1.0(0.34,3.7)^{*}$ & $0.46(0.16,3.9)$ & $0.72(0.53,1.31)$ \\
\hline Leptin to Adiponectin ratio & $0.27(0.08,2.7)$ & $0.98(0.20,3.0)^{*}$ & $0.33(0.06,0.76)$ & $0.85(0.67,11.0)$ \\
\hline Body Fat (\%) & $23.4,(9.9,36.2)$ & $38.3(32.0,46.7)^{*}$ & $27.4(8.3,38.1)$ & $37.1(28.5,40.2)$ \\
\hline VCAM (ng/mL) & $1058(561,1727)$ & $818(425,1730)$ & $856(586,1207)$ & $989(490,1697)$ \\
\hline ICAM (ng/mL) & $459(254,661)$ & $418(294,1079)$ & $500(265,952)$ & $398(324,598)$ \\
\hline \multicolumn{5}{|l|}{ MS } \\
\hline Yes/No & $0 / 17$ & $4 / 11$ & $1 / 11$ & $2 / 3$ \\
\hline
\end{tabular}

Values are median (min, max); Abbreviations: MS Metabolic syndrome, HOMA-IR Homeostatic Model Assessment of Insulin Resistance, VCAM Vascular cell adhesion

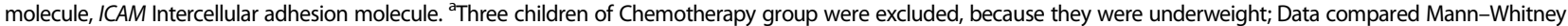
U-test and categorized data were analyzed using Fisher's Test, ${ }^{*} p$ value $<0.05$; ${ }^{b}$ lt was not possible to compare statistically (sample size) 
Table 4 Metabolic characteristics of child survivors of leukemia and lymphoma according to treatment at 6-months

\begin{tabular}{|c|c|c|c|c|}
\hline \multirow[b]{3}{*}{ Variables } & \multicolumn{4}{|l|}{ Treatment } \\
\hline & \multicolumn{2}{|c|}{ Chemotherapy $^{a} n=32$} & \multicolumn{2}{|c|}{ Chemotherapy plus radiotherapy $n=17$} \\
\hline & Normal & Overweigth/Obese & Normal & Overweigth/Obese \\
\hline n: number (\%) & 18 & $14(40)$ & 9 & $8(47)$ \\
\hline Sex: M & 13 & 11 & 6 & 7 \\
\hline Current age $(Y)$ & $12.5(8.0,17.1)$ & $11.6(8.0,17.1)$ & $14.0(8.4,17.0)$ & $13.0(8.1,18.0)$ \\
\hline Age at cancer diagnosis $(\mathrm{Y})$ & $6.0(2,13)$ & $4.0(2,12)$ & $6.0(0.08,12)$ & $70(1.0,11.1)$ \\
\hline Time since completion of therapy $(Y)$ & $4.0(2.1,5.0)$ & $4.0(2.1,5.0)$ & $3.1(3.0,5.0)$ & $4.0(2.0,5.0)$ \\
\hline$\Delta$ Body weight (kg) (6 mo - first assessement) & $1.6(-2.5,5.3)$ & & $2.0(-1.2,5.1)$ & \\
\hline$\Delta$ Height (cm) (6 mo - first assessment) & $2.6(1.7,6.0)$ & & $1.0(0.2,3.5)^{*}$ & \\
\hline Diagnosis : ALL/Lymphoma & $11 / 7$ & $9 / 5$ & $3 / 6$ & $2 / 6$ \\
\hline \multicolumn{5}{|l|}{ Pubertal stage } \\
\hline 1 & 8 & 9 & 3 & 2 \\
\hline$\geq 2$ & 10 & 5 & 6 & 6 \\
\hline \multicolumn{5}{|l|}{ MS Components } \\
\hline$W C(p c)$ & $25(10,50)$ & $90(35,100)^{*}$ & $30(10,50)$ & $83(50,90)^{* *}$ \\
\hline $\mathrm{SBP}(\mathrm{pc})$ & $15.5(0,55)$ & $64(2,95)^{*}$ & $13(1,38)$ & $21(3,65)$ \\
\hline $\mathrm{DBP}(p c)$ & $54(22,92)$ & $87(13,99)^{*}$ & $53(38,79)$ & $71(39,85)$ \\
\hline Triglicerydes (mg/dL) & $80(28,191)$ & $124(66,264)^{*}$ & $91(28,259)$ & $105(56,218)$ \\
\hline $\mathrm{HDL}-\mathrm{C}(\mathrm{mg} / \mathrm{dL})$ & $47.3(24.6,79.5)$ & $38.5(21.7,67.6)^{*}$ & $46(32,56)$ & $37(20,60)$ \\
\hline Glucose (mg/dL) & $93(76.6,102)$ & $97.5(83.5,115)$ & $88.5(76.6,100.6)$ & $92.6(82.7,101.2)$ \\
\hline \multicolumn{5}{|l|}{ Others metabolic variables } \\
\hline Insulin $(\mu \mathrm{U} / \mathrm{mL})$ & $25(8.3,35.4)$ & $33.4(22.8,64)^{*}$ & $14.9(3.4,43.9)$ & $28.9(16.9,52.3)$ \\
\hline HOMA-IR & $4.8(1.7,7.0)$ & $7.8(5.2,15.4)^{*}$ & $3.4(0.68,10.9)$ & $6.6(4.0,11.4)$ \\
\hline Adiponectin $(\mu \mathrm{g} / \mathrm{mL})$ & $21.9(7.7,42.1)$ & $20.2(6.6,57.3)$ & $20.9(11.6,28.9)$ & $15.3(0.64,33.0)$ \\
\hline Adiponectin per $\mathrm{Kg}$ fat $(\mu \mathrm{g} / \mathrm{mL} / \mathrm{kg})$ & $1.7(0.45,14.3)$ & $1.0(0.27,4.2)$ & $1.9(0.62,4.2)$ & $0.78(0.06,6.6)$ \\
\hline Leptin $((\mu \mathrm{g} / \mathrm{mL})$ & $5.2(1.8,30.9)$ & $21(9.4,40.7)^{*}$ & $6.2(1.6,25.1)$ & $9.5(3.6,27.6)$ \\
\hline Leptin per $\mathrm{Kg}$ fat $(\mu \mathrm{g} / \mathrm{mL} / \mathrm{kg})$ & $0.63(0.13,2.6)$ & $1.1(0.30,4.4)^{*}$ & $0.39(0.11,4.8)$ & $0.67(0.13,4.2)$ \\
\hline Leptin to Adiponectin ratio & $0.26(0.05,1.1)$ & $1.2(0.81,3.5)^{*}$ & $0.34(0.11,1.2)$ & $0.93(0.11,10.4)$ \\
\hline Body Fat (\%) & $22(11.2,35.7)$ & $39.8(33.4,49.3)^{*}$ & $23(10.9,43.4)$ & $30.7(18.7,37.7)$ \\
\hline VCAM (ng/mL) & $801(503,2045)$ & $818(514,1522)$ & $617(377,1166)$ & $727(394,1178)$ \\
\hline ICAM (ng/mL) & $404(234,753)$ & $440(200.1124)$ & $571(184,966)$ & $411(307,1037)$ \\
\hline \multicolumn{5}{|l|}{ MS } \\
\hline Yes/No & $0 / 18$ & $7 / 14$ & $0 / 9$ & $3 / 5$ \\
\hline
\end{tabular}

Values are median (min, max); Abbreviations: MS Metabolic syndrome, HOMA-IR Homeostatic Model Assessment of Insulin Resistance, VCAM Vascular cell adhesion molecule, ICAM Intercellular adhesion molecule. Data compared Mann-Whitney U-test. Categorized Data were analyzed using Fisher's Test. ${ }^{a}$ Three children of Chemotherapy group were excluded, because they were underweight; ${ }^{*} p$ value $<0.05 ;{ }^{* *} p$ value $=0.065$

chemotherapy only, of whom 15 (47\%) were classified as overweight or obese. All of the metabolic syndrome components were similar in the chemotherapy group (normal group vs overweight/obese group), except for waist circumference $(p<0.0001)$ and other metabolic variables such as insulin level $(16.3 \mu \mathrm{U} / \mathrm{mL}$ vs $24.9 \mu \mathrm{U} / \mathrm{mL}, p=$ 0.010), HOMA-IR index (3.6 vs 5.5, $p=0.033$ ), leptin level $(4.4 \mathrm{ng} / \mathrm{mL}$ vs $18.2 \mathrm{ng} / \mathrm{mL}, \quad p<0.0001)$, leptin-toadiponectin ratio $(0.27$ vs $0.98, p<0.0001)$, and fat mass percentage (23.4 vs $38.3, p<0.001)$. However, the group of children who received chemotherapy plus radiotherapy could not be statistically compared because only five (29\%) of the 17 children were classified into the overweight/obese subgroup. However, the overweight/obese children tended to exhibit higher values than the healthy children did, in terms of insulin levels $(20.5 \mu \mathrm{U} / \mathrm{mL}$ vs $36.3 \mu \mathrm{U} / \mathrm{mL}$ ), HOMA-IR index (4.3 vs 8.3), and leptin level $(7.4 \mathrm{pg} / \mathrm{mL}$ vs $17.5 \mathrm{pg} / \mathrm{mL}$ ) (Table 3). The analysis of changes in weight and height between the baseline measurement and 6 months after treatment according to the 
type of therapy received revealed significant differences in height. The height of the children in the chemotherapy group increased by $2.6 \mathrm{~cm}$ (range: 1.7-6.0), while that of the children in the radiotherapy plus chemotherapy group showed a growth of $1.0 \mathrm{~cm}$ (range: $0.2-3.5 ; p=0.035$ ) (Table 4). We wish to indicate that age did not significantly differ between the treatment groups. At 6 months, all of the metabolic syndrome components were similar in the chemotherapy plus radiotherapy group (normal group vs overweight/obese group).

In the Table 5 are shown the analysis of the MS components and the aforementioned metabolic variables compared with biomarkers expressed in tertiles indicated that children who were classified in the highest tertile for BFP, leptin, and leptin/adiponectin ratio had a higher WC and higher levels of triglycerides, insulin, and HOMA index. Children in the highest tertile of the HOMA index had lower levels of adiponectin, and higher waist circumference, triglycerides, and leptin levels compared to children who were in the lowest tertile of the HOMA index.

At 6 months, utilizing the tertile without changes as a reference (Table 6), children who reduced their BFP also reduced their WC and insulin concentration. However, the children who increased HOMA index values had a $2.5 \mathrm{~cm}$ greater WC, $5.1 \mathrm{mg} / \mathrm{dL}$ higher glucose, and $30 \mathrm{mg} / \mathrm{dL}$ higher triglycerides. In contrast to these findings, when children reduced their leptin concentrations, their glucose levels decreased. On the contrary, when they reduced their adiponectin values, their HDL-C levels also decreased. Similarly, when the leptin/adiponectin ratio tertile decreased, decreases in the levels of glucose, triglycerides, fasting insulin and HOMA index were also observed.

Table 7 shows that the odds of developing MS at the first assessment were higher in those with a BFP (OR 5.1, 95\% CI 1.9 to 22.0), leptin level (OR 4.8, 95\% CI 1.4 to 17.2 ) and leptin/adiponectin ratio (OR $5.295 \%$ CI 1.2 to 22.6) in the highest tertile, whereas the lowest tertile of adiponectin was associated with a protective but not significant effect. Similar findings were also observed after 6 months. The HOMA index only was a predictive factor of developing MS at 6 months.

\section{Discussion}

Our study showed that during early surveillance, the adiposity, HOMA-IR index, concentration of leptin, and leptin/adiponectin ratio are strongly associated with MS development in children surviving lymphoma and ALL. In contrast, the adiponectin concentration seems to have a protective effect on the development of this syndrome.

In our sample of child cancer survivors, the estimated frequencies of MS tended to be greater than those observed by Kourti (5.8\%) [22], Trimis [23] (11.2\%), Chow [24] (10.8\%) and Aldhafiri [25] (7.1, 5.4\%) and similar to those reported by Reisi [26] (20\%). This variation in the frequency of MS is principally due to the lack of consistent criteria and cutoff points in its definition. However, our results are similar to several studies conducted in Mexico in an open pediatric population that used the same definition. For example, the Juarez et al. study [27], reports a prevalence of $20 \%$ in children and obese adolescents with ages from 11 to 13 years, whereas Klunder et al. [14] reported a prevalence of $13 \%$ in obese children $6-12$ years.

In our Country, there are no statistics regarding the number of survivors of childhood cancer reaching adulthood. However, within the Hematology and Oncology Services at our hospital, we observed a gradual increase in this group of patients. Mexico is a country with the highest prevalence of overweight and obesity in the world. In this context, MS is considered to be a complex clinical condition that is associated with early obesity and other metabolic risk factors associated with the start of its development during childhood. In various studies, an increase in the frequency of obesity in survivors of childhood cancer has been observed [3, 28]. We also found that the percentages of leukemia and lymphoma survivors presented combined prevalence rates of overweight and obesity that were slightly greater (38 and 42\%) than those reported by the National Health Survey (ENSANUT 2012) [29] in a Mexican pediatric population (35\%). This finding is relevant given that central obesity can cause insulin resistance, a metabolic alteration that is found in the majority of individuals with MS and which increases the risk of type 2 diabetes and cardiovascular disease [30, 31 ]. In this study, approximately $80 \%$ of the surviving youths presented high levels of insulin and resistance to insulin. In these children, hyperinsulinemia compensates for insulin resistance and maintains the homeostasis of insulin. However, even without alterations in the metabolism of glucose, the risk of presenting with additional health problems exists, such as early atherosclerosis, hypertension, and so on.

Currently, given the increase in complications associated with MS, various molecules have been proposed to predict the risk of this syndrome in both general population and pediatric cancer survivor patients. The main observations of this study were that childhood cancer survivors in the highest tertile of the leptin/adiponectin ratio, BFP, and HOMA index presented with lower levels of adiponectin per $/ \mathrm{kg} / \mathrm{fat}$, a greater waist circumference, high concentrations of leptin and triglycerides, a higher systolic blood pressure and lower HDL-C concentrations. In this study, BFP and the leptin-to- 


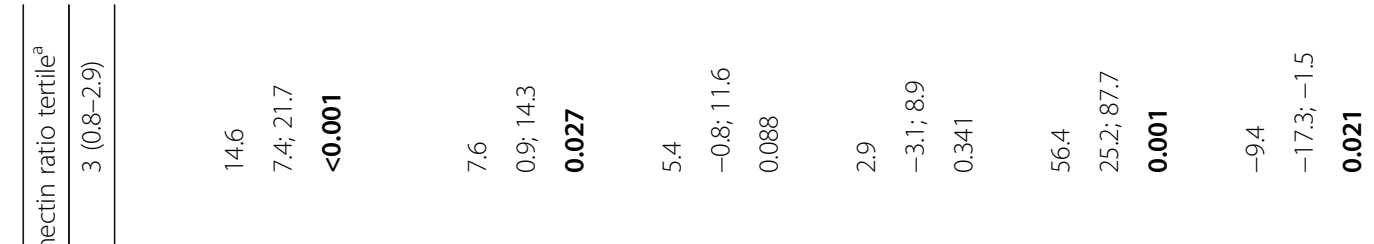

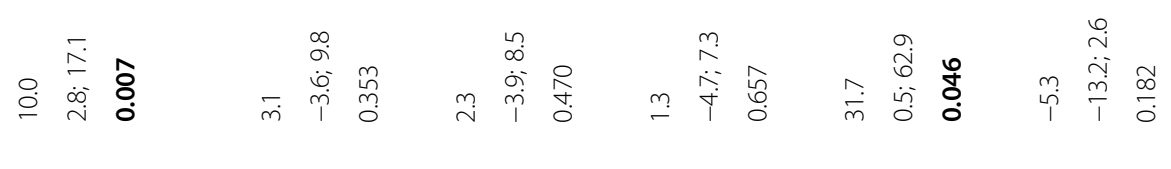

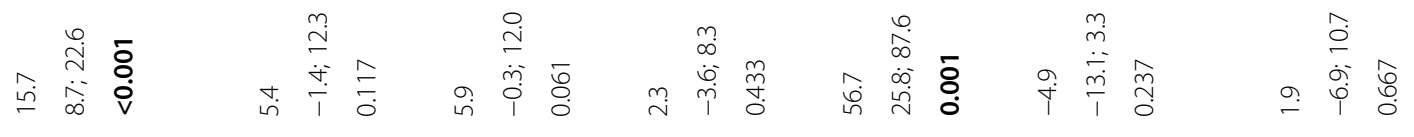

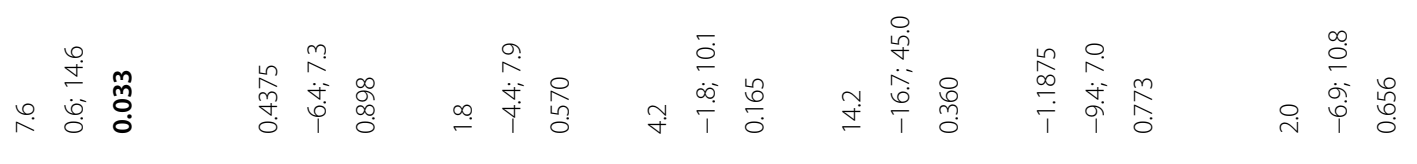

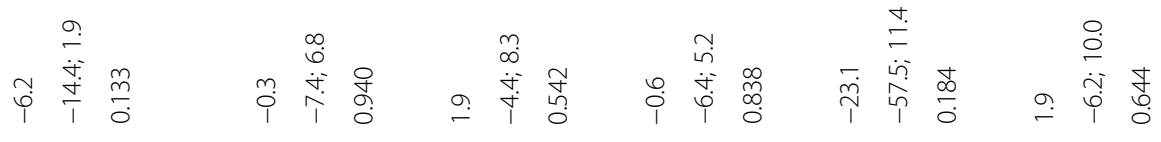

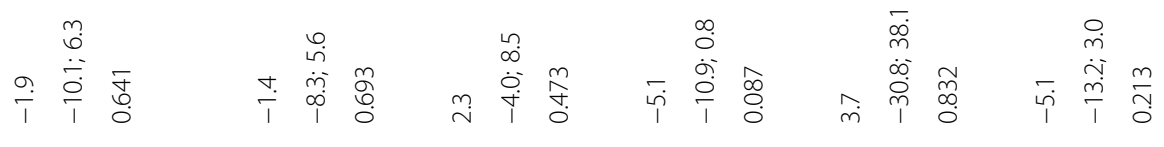

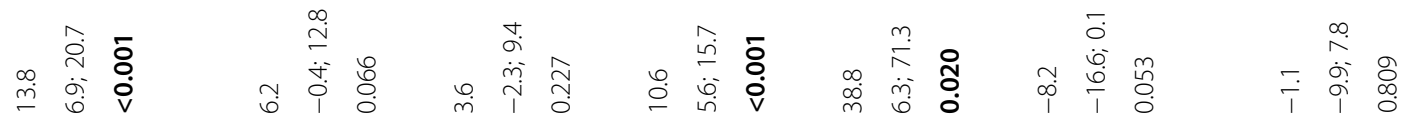

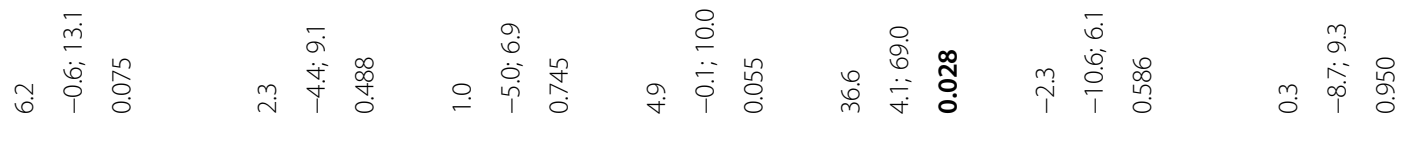

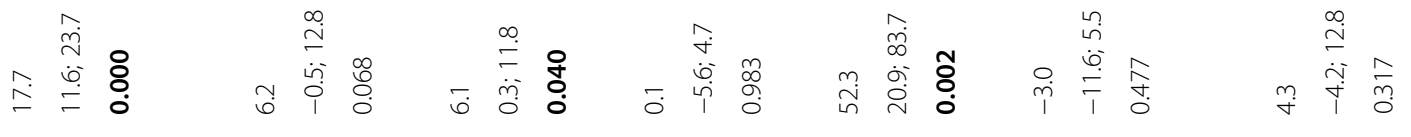




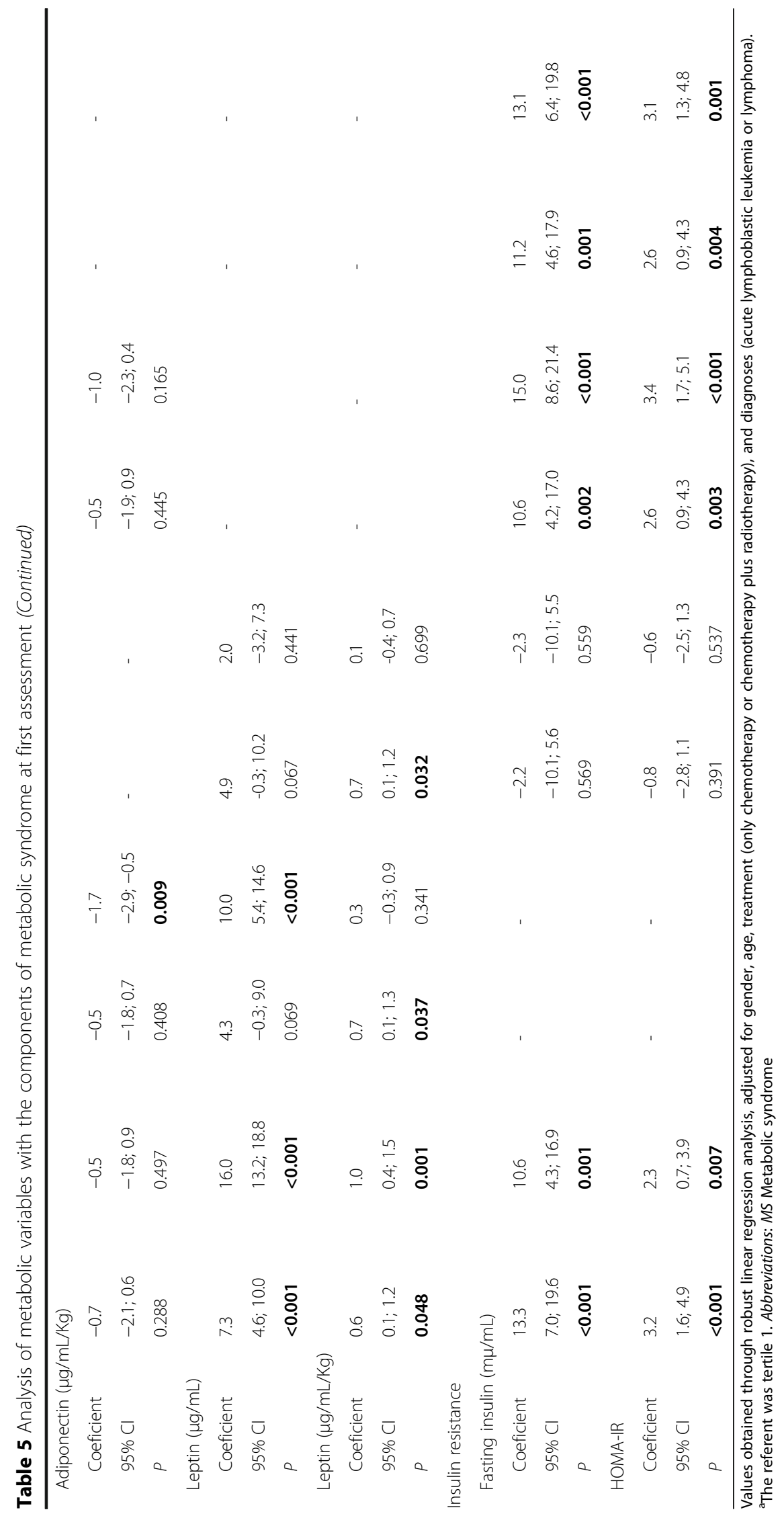


Table 6 Analysis of metabolic variables with the components of metabolic syndrome at 6-months

\begin{tabular}{|c|c|c|c|c|c|c|c|c|c|c|}
\hline \multirow[t]{2}{*}{$\begin{array}{l}\text { Outcome } \\
\text { variables }\end{array}$} & \multicolumn{2}{|c|}{$\begin{array}{l}\text { Fat percentage Change } \\
\text { tertiles (values) }\end{array}$} & \multicolumn{2}{|c|}{$\begin{array}{l}\text { HOMA-IR Change } \\
\text { tertiles (values) } \\
\end{array}$} & \multicolumn{2}{|c|}{$\begin{array}{l}\text { Adiponectin Change } \\
\text { tertile (values) }\end{array}$} & \multicolumn{2}{|l|}{$\begin{array}{l}\text { Leptin Change } \\
\text { tertile (values) }\end{array}$} & \multicolumn{2}{|c|}{$\begin{array}{l}\text { Leptin adiponectin } \\
\text { ratio tertile (values) } \\
\end{array}$} \\
\hline & $\begin{array}{l}\text { Decreased } \\
(-5.9--0.7)\end{array}$ & $\begin{array}{l}\text { Increased } \\
(1.3-5.6)\end{array}$ & $\begin{array}{l}\text { Decreased } \\
(-7.2-0.2)\end{array}$ & $\begin{array}{l}\text { Increased } \\
(1.8-7.3)\end{array}$ & $\begin{array}{l}\text { Decreased } \\
(-55.6--3.2)\end{array}$ & $\begin{array}{l}\text { Increased } \\
(2.1-21.9)\end{array}$ & $\begin{array}{l}\text { Decreased } \\
(-13.4--0.4)\end{array}$ & $\begin{array}{l}\text { Increased } \\
(2.7-17.5)\end{array}$ & $\begin{array}{l}\text { Decreased } \\
(-1.1--0.01)\end{array}$ & $\begin{array}{l}\text { Increased } \\
(0.1-1.5)\end{array}$ \\
\hline \multicolumn{11}{|l|}{ MS } \\
\hline \multicolumn{11}{|c|}{ Waist circumference (cm) } \\
\hline Coeficient & -3.8 & 0.6 & -0.1 & 2.5 & -0.3 & 0.6 & -0.1 & 2.7 & -1.5 & 2.5 \\
\hline $95 \% \mathrm{Cl}$ & $-6.2 ;-1.4$ & $-1.7 ; 2.8$ & $-2.4 ; 2.3$ & $0.1 ; 4.9$ & $-2.9 ; 2.4$ & $-2.2 ; 3.3$ & $-2.6 ; 2.5$ & $0.1 ; 5.3$ & $-3.9 ; 0.9$ & $0.1 ; 5.0$ \\
\hline$P$ & 0.003 & 0.623 & 0.950 & 0.041 & 0.850 & 0.668 & 0.963 & 0.041 & 0.218 & 0.042 \\
\hline \multicolumn{11}{|c|}{ Blood Pressure (mmHg) } \\
\hline \multicolumn{11}{|l|}{ Systolic BP } \\
\hline Coeficient & 0.1 & -6.8 & 5.1 & 6.7 & -3.5 & -4.0 & -3.5 & -1.7 & -7.3 & -5.4 \\
\hline $95 \% \mathrm{Cl}$ & $-9.2 ; 9.5$ & $-15.5 ; 1.9$ & $-2.8 ; 13.1$ & $-1.3 ; 14.6$ & $-12.3 ; 5.3$ & $-12.8 ; 4.8$ & $-12.5 ; 5.6$ & $-10.9 ; 7.5$ & $-16.1 ; 1.6$ & $-14.3 ; 3.6$ \\
\hline$P$ & 0.975 & 0.123 & 0.202 & 0.098 & 0.425 & 0.361 & 0.447 & 0.709 & 0.104 & 0.235 \\
\hline \multicolumn{11}{|l|}{ Diastolic BP } \\
\hline Coeficient & -5.6 & -7.7 & 6.1 & 3.6 & -2.9 & 2.2 & -5.1 & -0.2 & -3.4 & -3.5 \\
\hline $95 \% \mathrm{Cl}$ & $-13.9 ; 2.6$ & $-15.3 ;-0.0$ & $-1.1 ; 13.3$ & $-3.5 ; 10.8$ & $-10.3 ; 4.5$ & $-5.1 ; 9.6$ & $-12.6 ; 2.4$ & $-7.9 ; 7.4$ & $-11.1 ; 4.2$ & $-11.3 ; 4.2$ \\
\hline$P$ & 0.175 & 0.049 & 0.093 & 0.312 & 0.433 & 0.542 & 0.180 & 0.955 & 0.375 & 0.366 \\
\hline \multicolumn{11}{|l|}{ Glucose } \\
\hline Coeficient & 0.3 & 1.9 & -5.5 & 5.1 & -2.0 & -1.7 & -6.9 & 1.7 & -5.9 & 1.5 \\
\hline $95 \% \mathrm{Cl}$ & $-6.4 ; 6.9$ & $-4.4 ; 8.1$ & $-10.4 ;-0.7$ & $0.2 ; 10.0$ & $-7.9 ; 4.0$ & $-7.8 ; 4.4$ & $-12.3 ;-1.5$ & $-3.7 ; 7.2$ & $-11.5 ; 0.4$ & $-4.1 ; 7.2$ \\
\hline P & 0.936 & 0.549 & 0.027 & 0.043 & 0.509 & 0.568 & 0.013 & 0.529 & 0.037 & 0.590 \\
\hline \multicolumn{11}{|l|}{ Triglycerides } \\
\hline Coeficient & -3.8 & -5.4 & -3.6 & 30.0 & 9.4 & 1.7 & -8.9 & 2.9 & -40.7 & -10.8 \\
\hline $95 \% \mathrm{Cl}$ & $-37.7 ; 30.2$ & $-37.6 ; 26.8$ & $-31.5 ; 24.3$ & $1.7 ; 58.3$ & $-22.2 ; 41.0$ & $-30.5 ; 33.8$ & $-41.1 ; 23.2$ & $-29.8 ; 35.5$ & $-70.4 ;-11.1$ & $-40.9 ; 19.4$ \\
\hline P & 0.823 & 0.738 & 0.797 & 0.038 & 0.551 & 0.918 & 0.579 & 0.861 & 0.008 & 0.476 \\
\hline \multicolumn{11}{|l|}{$\mathrm{HDL}-\mathrm{C}$} \\
\hline Coeficient & 0.6 & -1.8 & 2.4 & 3.6 & -8.3 & -0.5 & 1.0 & 3.0 & 2.6 & 0.3 \\
\hline $95 \% \mathrm{Cl}$ & $-7.1 ; 8.4$ & $-9.0 ; 5.4$ & $-4.2 ; 9.0$ & $-3.2 ; 10.4$ & $-14.5 ;-2.1$ & $-6.9 ; 5.9$ & $-6.0 ; 8.0$ & $-4.2 ; 10.2$ & $-4.4 ; 9.6$ & $-6.9 ; 7.6$ \\
\hline P & 0.867 & 0.620 & 0.469 & 0.288 & 0.010 & 0.886 & 0.770 & 0.401 & 0.453 & 0.926 \\
\hline \multicolumn{11}{|l|}{ Adipokines } \\
\hline \multicolumn{11}{|l|}{ Adiponectin } \\
\hline Coeficient & 0.1 & -3.9 & 5.8 & 2.5 & - & - & -1.2 & -2.4 & - & - \\
\hline $95 \% \mathrm{Cl}$ & $-4.0 ; 4.8$ & $-9.0 ; 1.3$ & $1.3 ; 10.3$ & $-2.3 ; 7.3$ & & & $-6.1 ; 3.8$ & $-7.4 ; 2.6$ & & \\
\hline P & 0.980 & 0.138 & 0.013 & 0.298 & & & 0.639 & 0.332 & & \\
\hline \multicolumn{11}{|l|}{ Leptin } \\
\hline Coeficient & 0.3 & 1.4 & -1.8 & 1.1 & 2.8 & 3.5 & - & - & - & - \\
\hline $95 \% \mathrm{Cl}$ & $-4.3 ; 4.9$ & $-2.9 ; 5.6$ & $-5.5 ; 1.9$ & $-2.8 ; 5.0$ & $-0.8 ; 6.5$ & $-0.2 ; 7.1$ & & & & \\
\hline$P$ & 0.895 & 0.511 & 0.331 & 0.569 & 0.130 & 0.063 & & & & \\
\hline \multicolumn{11}{|l|}{ Insulin resistance } \\
\hline \multicolumn{11}{|c|}{ Fasting insulin $(\mathrm{m} \mu / \mathrm{mL})$} \\
\hline Coeficient & -6.9 & 0.1 & - & - & -1.1 & -6.3 & -4.1 & 2.5 & -7.6 & 2.4 \\
\hline $95 \% \mathrm{Cl}$ & $-12.7 ;-1.1$ & $-5.8 ; 6.0$ & & & $-7.8 ; 5.7$ & $-13.2 ; 0.6$ & $-11.1 ; 2.9$ & $-4.6 ; 9.6$ & $-14.1 ;-1.1$ & $-4.3 ; 9.0$ \\
\hline$P$ & 0.020 & 0.978 & & & 0.753 & 0.072 & 0.241 & 0.480 & 0.023 & 0.476 \\
\hline
\end{tabular}


Table 6 Analysis of metabolic variables with the components of metabolic syndrome at 6-months (Continued)

\begin{tabular}{|c|c|c|c|c|c|c|c|c|c|c|}
\hline \multicolumn{11}{|l|}{ HOMA-IR } \\
\hline Coeficient & 1.8 & 1.7 & - & - & -0.4 & -1.7 & -1.1 & 0.9 & -2.2 & 0.8 \\
\hline $95 \% \mathrm{Cl}$ & $0.1 ; 3.4$ & $0.1 ; 3.4$ & & & $-2.2 ; 1.5$ & $-3.6 ; 0.2$ & $-3.1 ; 0.8$ & $-1.0 ; 2.9$ & $-3.9 ;-0.4$ & $-1.0 ; 2.6$ \\
\hline P & 0.033 & 0.043 & & & 0.708 & 0.083 & 0.237 & 0.345 & 0.017 & 0.387 \\
\hline
\end{tabular}

Values obtained through robust linear regression analysis, adjusted for gender, age, treatment (only chemotherapy or chemotherapy plus radiotherapy), and and diagnoses (acute lymphoblastic leukemia or lymphoma). Regression coefficients are change in outcome variable per tertile change in fat percentage, HOMA-IR Adiponectin, leptin, and Leptin adiponectin ratio. The referent was stable tertile

adiponectin ratio were strong predictors of MS, with odds ratios of 9 and 9.4, respectively. For this reason, the measurement of these metabolic variables in early surveillance screenings can be useful to identify individuals who are susceptible to metabolic risk. In the leptin/adiponectin relationship, this measurement can be considered to be an indicator of sensitivity to insulin in youth who have survived childhood cancer. However, it should be noted that adiponectin, an adipocytokine with antiatherogenic, antidiabetogenic, and antiinflammatory functions that is known as a predictor of MS in children [7, 14, 32] did not show this association. This observation can most likely be explained by the high number of participants who presented with IR, as previous studies revealed that individuals with IR present lower serum levels of adiponectin, independent of sex, age and ethnicity [33,34]. Similarly, the change in these indicators demonstrated a direct effect on the metabolic profiles of children. In contrast, an increase in the concentration of adiponectin at 6 months showed a trend toward reduced concentrations of insulin and HOMA index, without reaching statistical significance. In child cancer survivors, few studies have evaluated the role of these adipokines, in addition to levels of insulin, adiposity and the presence of MS. Tonorezos et al. [35], in a cross-sectional study of 116 adult survivors of childhood leukemia (median age, 23 years), reported that survivors presented high levels of leptin associated with body fat and insulin resistance. In a more recent study that is similar to ours, Kojima et al. [36] reported that low levels of total adiponectin were associated with a greater number of patients with hypertriglyceridemia and hypertension.
Based on these results, we should discuss the strengths and limitations of our work. Given the nature of the study, survival bias could not be avoided, as only patients who were alive at the time of the study was conducted could be evaluated. This bias is important because in developing countries, such as Mexico, the survival rate of children with ALL at 5 years is less than that reported in developed countries (73 vs 90\%) [37]. Therefore, our findings could not be extrapolated to developed countries. However, in developing countries with survival rates similar to ours, the results could have external validity. It was also difficult to determine whether the percentage of obesity found in these children is primarily related to the treatment received (chemotherapy, radiation therapy or both), as the nutritional state of the metabolic variables at the time of diagnosis and during treatment is not known. However, currently, various studies conducted in this population have indicated an increase in the incidence of obesity and resistance to insulin related to treatment in ALL and lymphoma survivors during therapy [38]. The development of these metabolic alterations has been related to a deficiency in the secretion of growth hormone, not only in those patients who received brain radiation but also in those who have received chemotherapy or stem cell transplants [6]. In this study, survivors of childhood ALL and lymphoma are at increased risk of short stature, the risk is highest for those treated with radiotherapy. Another possible explanation for the increased risk of developing components of MS in this population is related to corticosteroid therapy, as it is widely accepted that children who receive steroids gain weight [6]. An additional limitation was that pubertal stage was

Table 7 Odds ratio of developing metabolic syndrome according to different metabolic variables

\begin{tabular}{|c|c|c|c|c|c|c|}
\hline \multirow[t]{2}{*}{ Variable } & \multicolumn{3}{|c|}{ First assessment } & \multicolumn{3}{|c|}{ After 6 months } \\
\hline & $\overline{\mathrm{OR}^{a}}$ & $95 \%$ IC & $P$ & $\mathrm{OR}^{\mathrm{a}}$ & $95 \%$ IC & $p$ \\
\hline Body fat percentage & 5.1 & $1.9 ; 22.0$ & 0.028 & 9.0 & $2.0 ; 41.1$ & 0.004 \\
\hline HOMA-IR index & 2.3 & $0.2 ; 1.4$ & 0.137 & 5.5 & $1.6 ; 19.3$ & 0.007 \\
\hline Leptin & 4.8 & $1.4 ; 17.2$ & 0.015 & 5.7 & $1.6 ; 20.2$ & 0.007 \\
\hline Adiponectin & 0.5 & $0.2 ; 1.5$ & 0.189 & 0.9 & $0.4 ; 2.0$ & 0.728 \\
\hline Leptin to adiponectin ratio & 5.2 & $1.2 ; 22.6$ & 0.027 & 9.4 & $2.0 ; 43.8$ & 0.004 \\
\hline
\end{tabular}

aR obtained through logistic regression, by tertil change and adjusted for gender, age, treatment (only chemotherapy or chemotherapy plus radiotherapy), and diagnoses (acute lymphoblastic leukemia or lymphoma) 
determined on the basis of the children's self-assessment using Tanner's standard photographs for pubic hair and genital development, which is a more subjective measure, as it depends on the patient's self-assessment. Validation studies showed that self-assessment is inferior to clinical assessment [39]. In addition, in this study, we have not analyzed what kinds of food they were eating and their physical activity. On the other hand, the presence of MS increases cardiovascular risk and vascular brain disease as a consequence of premature changes in the arterial wall, including endothelial cell damage [40]. In this sample of child cancer survivors, endothelial function (in terms of VCAM and ICAM) was not different between those who received only chemotherapy and those who received radiation therapy and between those who were diagnosed with MS and those who did not develop MS. To validate that the findings were not due to chance, a second measurement at 6 months was conducted. This second measurement confirmed that most of the findings observed in the first measurement were stable at 6 months. Variables such as BFP were obtained using the DXA technique, which is considered to be reliable and precise in children. With regard to the metabolic and biochemical variables, standard techniques were employed to quantify their concentration in a specialized research laboratory. It was determined that a greater number of metabolic variables were reported than in other studies.

\section{Conclusions}

Biomarkers such as HOMA-IR, leptin and leptin/adiponectin are associated with each of the components of the MS and with a heightened risk of suffering MS among children survivors of cancer. Given the close relationship between MS with risk of developing type 2 diabetes and cardiovascular diseases, it is imperative to implement prevention measures in this population and especially in developing countries where these pathologies have become the leading cause of death.

\section{Abbreviations \\ ALL: Acute linfoblastic leukemia; BFP: Body fat percentage; BMI: Body mass index; CDC: Center for disease control and prevention; DXA: Dual energy $X$ ray absorptiometry; HDL-C: High density lipoprotein cholesterol; HOMA- IR: Homeostatic model assessment insulin resistance; iCAM: Intracellular adhesion molecule; IR: Insulin resistance; MS: Metabolic syndrome; OR: Odds ratio; VCAM: Vascular cell adhesion molecule; WC: Waist circumference}

\section{Acknowledgements}

The authors would like to thank coworkers from Hematology Service (Lourdes Vargas).

\section{Funding}

This research was supported by a Grant from Consejo Nacional de Ciencia y Tecnología (CONACyT) (2005-1-13980). The funding body did not participate in the design of the study, interpretation and in writing the manuscript.

\section{Availability of data and materials}

The datasets supporting the conclusions of this article are included within the article, but are available from the corresponding author on reasonable request.

\section{Authors' contributions}

LBC, designed the study, analyzed data, obtained funding, and prepared the manuscript; MLA, JMA, contributed to the analysis and interpretation of data and helped prepare the manuscript; MKK, performed the analysis and interpretation of data, and helped prepare the manuscript; MCRZ, RBR, HRM, JMT, JSH, KSL, ELA, human resource management, contributed to the analysis and interpretation of data, AVM, GMG contributed to the acquisition of data. All authors make intellectually contributions through processed of manuscript preparation, and they read and approved the final manuscript to be submitted.

\section{Competing interests}

The authors declare that they have no competing interests.

\section{Consent for publication}

Not applicable.

\section{Ethics approval and consent to participate}

This study was approved by the Research and Ethics Committee of the Pediatric Hospital at the Mexican Social Security Institute (2005/3603/071). We obtained written informed consent from parents and informed assent from children

\section{Author details}

${ }^{1}$ Medical Nutrition Research Unit, 21st Century Pediatric Hospital, National Medical Center, MexicanInstitute of Social Security, México City, México. ${ }^{2}$ Health Research Coordination, 21st Century Pediatric Hospital, National Medical Center, Mexican Institute of Social Security, México City, México. ${ }^{3}$ Department of Community Health Research, Federico Gómez Children's, México Secretary of Health, and Research Committee, Latin American Society for Pediatric Gastroenterology, Hepatology and Nutrition (LASPGHAN), México City, México. ${ }^{4}$ Department of Hematology, Pediatric Hospital, 21st Century National Medical Center, Mexican Institute of Social Security, México City, México. ${ }^{5}$ Department of Hemato-Oncology, General Hospital of México, México Secretary of Health, México City, México. ${ }^{6}$ Department of Oncology, Pediatric Hospital, 21st Century National Medical Center, Mexican Institute of Social Security, México City, México. ${ }^{7}$ Medical Nutrition Research Unit, 21st Century Pediatric Hospital, National Medical Center, Mexican Institute of Social Security, Avenida Cuauhtémoc 330 Col. Doctores, México City C.P. 06720, México.

Received: 24 December 2015 Accepted: 31 January 2017

Published online: 13 February 2017

\section{References}

1. Lughetti L, Bruzzi P, Predieri B, Paolucci P. Obesity in patients with acute leukemia in childhood. Ital J Pediatr. 2012;38:4

2. Jung HS, Myung SK, Kim BS, Seo HG. Metabolic syndrome in adult cancer survivors: a meta-analysis. Diabetes Res ClinPract. 2012;95(2):275-82.

3. vanWaas M, Neggers SJ, van der Lelij AJ, Pieters R, van den Heuvel-Eibrink $\mathrm{MM}$. The metabolic syndrome in adult survivors of childhood cancer, a review. J Pediatr HematolOncol. 2010;32(3):171-9.

4. Oudin C, Simeoni MC, Sirvent N, Contet A, Begu-Le Coroller A, Bordigoni P, Curtillet C, Poirée M, Thuret I, Play B, Massot MC, Chastagner P, Chambost H, Auquier $P$, Michel $G$. Prevalence and risk factors of the metabolic syndrome in adult survivors of childhood leukemia. Blood. 2011;117:4442-8.

5. Lee S, Gungor N, Bacha F, Arslanian S. Insulin resistance: link to the components of the metabolic syndrome and biomarkers of endothelial dysfunction in youth. Diabetes Care. 2007;30(8):2091-7.

6. Mi J, Munkonda MN, Li M, Zhang MX, Zhao XY, Wamba Fouejeu PC, Cianflone K. Adiponectin and leptin metabolic biomarkers in chinese children and adolescents. J Obes. 2010. doi:10.1155/2010/892081.

7. Körner A, Kratzsch J, Gausche R, Schaab M, Erbs S, Kiess W. New predictors of the metabolic syndrome in children-role of adipocytokines. Pediatr Res. 2007;61(6):640-5.

8. Valle M, Martos R, Gascón F, Cañete R, Zafra MA, Morales R. Low-grade systemic inflammation, hypoadiponectinemia and a high concentration of 
leptin are present in very young obese children, and correlate with metabolic syndrome. Diabetes Metab. 2005;31:55-62.

9. Oeffinger KC, Adams-Huet B, Victor RG, Church TS, Snell PG, Dunn AL, Eshelman-Kent DA, Ross R, Janiszewski PM, Turoff AJ, Brooks S, Vega GL. Insulin resistance and risk factors for cardiovascular disease in young adult survivors of childhood acute lymphoblastic leukemia. J Clin Oncol. 2009;27(22):3698-704.

10. Beauloye V, Zech F, Tran HT, Clapuyt P, Maes M, Brichard SM. Determinants of early atherosclerosis in obese children and adolescents. J Clin Endocrinol Metab. 2007;92(8):3025-32

11. Coffman E, Richmond-Bryant J. Multiple biomarker models for improved risk estimation of specific cardiovascular diseases related to metabolic syndrome: a cross-sectional study. Popul Health Metr. 2015;13:7.

12. MacArthur AC, Spinelli JJ, Rogers PC, Goddard KJ, Abanto ZU, McBride ML, et al. Mortality among 5-years survivors of cancer diagnosed during childhood or adolescence in British Columbia, Canada. Pediatr Blood Cancer. 2007;48(4):460-7.

13. Mulrooney DA, Yeazel WM, Kawashima T, Mertens AC, Mitby P, Stovall M, Donaldson SS, Green DM, Sklar CA, Robison LL, Leisenring WM. Cardiac outcomes in a cohort of adult survivors of childhood and adolescent cancer: retrospective analysis of the childhood cancer survivor study cohort. BMJ. 2009;339:b606.

14. Klunder-Klunder M, Flores-Huerta S, Garcia-Macedo R, Peralta-Romero J, Cruz M. Adiponectin in eutrophic and obese children as a biomarker to predict metabolic syndrome and each of its components. BMC Public Health. 2013; 13:88. doi:10.1186/1471-2458-13-88.

15. Fernández JR, Redden DT, Pietrobelli A, Allison DB. Waist circumference percentiles in nationally representative samples of African-American, European-American, and Mexican-American children and adolescents. J Pediatr. 2004;145(4):439-44.

16. Kuczmarski RJ, Ogden CL, Grummer-Strawn LM, et al. CDC growth charts: United States. Adv Data. 2000;314:1-27.

17. Marshall WA, Tanner JM. Growth and physiological development during adolescence. Annu Rev Med. 1968;19:283-300.

18. Zimmet P, Alberti G, Kaufman F, Tajima N, Silink M, Arslanian S, Wong G, Bennett $P$, Shaw J, Caprio $S$. The metabolic syndrome in children and adolescents. Lancet. 2007;369:2059-61.

19. Falkner B, Daniels SR, Flynn JT, Gidding S, Green LA, Ingelfinger JR, Rocchini AP. National High Blood Pressure Education Program Working Group on High Blood Pressure in Children and Adolescents, "The fourth report on the diagnosis, evaluation, and treatment of high blood pressure in children and adolescents". Pediatrics. 2004;114(Suppl 2):555-576.

20. Keskin M, Kurtoglu S, Kendirci M, Atabek ME, Yazici C. Homeostasis model assessment is more reliable than the fasting glucose/insulin ratio and quantitative insulin sensitivity check index for assessing insulin resistance among obese children and adolescents. Pediatrics. 2005;115(4):e500-3.

21. Aradillas GC, Rodríguez MM, Garay SM, Malacara JM, Rascon-Pacheco RA, Guerrero-Romero F. Distribution of the homeostasis model assessment of insulin resistance in Mexican children and adolescents. Eur J Endocrinol. 2012;166(2):301-6.

22. Kourti M, Tragiannidis A, Makedou A, Papageorgiou T, Rousso I, Athanassiadou F. Metabolic syndrome in children and adolescents with a acute lymphoblastic leukemia after the completion of chemotherapy. J PediatrHematol Oncol. 2005;27(9):449-501.

23. Trimis G, Moschovic M, Papassotiriou I, Chrousos G, TzortzatouStathopoulou F. Early indicators of dysmetabolic syndrome in young survivors of acute lymphoblastic leukemia in childhood as a target for preventive disease. J Pediatr Hematol Oncol. 2007;29(5):309-14.

24. Chow EJ, Pihoker C, Hunt K, Wilkinson K, Friedman DL. Obesity and hypertension among children after treatment for acute lymphoblastic leukemia. Cancer. 2007;110(10):2313-20.

25. Aldhafiri F, Al-Nasser A, Al-Sugair A, Al-Mutairi H, Young D, Reilly JJ. Obesity and metabolic syndrome in adolescent survivors of standard risk childhood acute lymphoblastic leukemia in Saudi Arabia. Pediatr Blood Cancer. 2012;59(1):133-7.

26. Reisi N, Azhir A, Hashemipour M, Raeissi P, Amini A, Moafi A. The metabolic syndrome in survivors of childhood acute lymphoblastic leukemia in Isfahan, Iran. J Res Med Sci. 2009;14(2):111-6.

27. Juárez-López C, Klünder-Klünder M, Medina-Bravo P, Madrigal-Azcárate A, Mass-Díaz E, Flores-Huerta S. Insulin resistance and its association with the components of metabolic syndrome among obese children and adolescents. BMC Public Health. 2010;10:318.

28. Zhang FF, Rodday AM, Kelly MJ, Must A, MacPherson C, Roberts SB, Saltzman E, Parsons SK. Predictors of being overweight or obese in survivors of pediatric acute lymphoblastic leukemia (ALL). Pediatr Blood Cancer. 2014; 61(7):1263-9.

29. Gutiérrez JP, Rivera-Dommarco J, Shamah-Levy T, Villalpando-Hernández S, Franco A, Cuevas-Nasu L, et al. Encuesta Nacional de Salud y Nutrición 2012. Resultados Nacionales. Cuernavaca: Instituto Nacional de Salud Pública; 2012.

30. Bizzarri C, Pinto RM, Ciccone S, Brescia LP, Locatelli F, Cappa M. Early and progressive insulin resistance in young, non-obese cancer survivors treated with hematopoietic stem cell transplantation. Pediatr Blood Cancer. 2015;62:1650-5.

31. Palomer X, Perez A, Blanco-Vaca F. Adiponectin: a new link between obesity, insulin resistance and cardiovascular disease. Med Clin. 2005;124(10):388-95.

32. Gilardini L, McTernan PG, Girola A, da Silva NF, Alberti L, Kumar S, Invitti C. Adiponectin is a candidate marker of metabolic syndrome in obese children and adolescents. Atherosclerosis. 2006;189(2):401-7.

33. Eyzaguirre F, Mericq V. Insulin resistance markers in children. Horm Res Paediatr. 2009:71:65-74.

34. Kim SM, Cho KH, Park HS. Relationship between plasma adiponectin levels and the metabolic syndrome among Korean people. Endocrine J. 2006;53(2):247-54

35. Tonorezos ES, Vega GL, Sklar CA, Chou JF, Moskowitz CS, Mo Q, Church TS, Ross R, Janiszewski PM, Oeffinger KC. Adipokines, body fatness, and insulin resistance among survivors of childhood leukemia. Pediatr Blood Cancer. 2012;58(1):31-6.

36. Kojima C, Kubota M, Nagai A, Adachi S, Watanabe K, Nakahata T. Adipocytokines in childhood cancer survivors and correlation with metabolic syndrome components. Pediatr Int. 2013;55(4):438-42.

37. Jiménez-Hernández E, Jaimes-Reyes EZ, Arellano-Galindo J, García-Jiménez X, Tiznado-García HM, Dueñas-González MT, et al. Survival of Mexican children with acute lymphoblastic leukaemia under treatment with the protocol from the Dana-Farber Cancer Institute 00-01. Biomed Res Int. 2015. doi:10.1155/2015/576950.

38. Esbenshade AJ, Simmons JH, Koyama T, Lindell RB, Friedman DL. Obesity and insulin resistance in pediatric acute lymphoblastic leukemia worsens during maintenance therapy. Pediatr Blood Cancer. 2013;60(8):1287-91.

39. Faria ERD, Franceschini SDCC, Peluzio MDCG, Sant'AnaLFDR, Priore SE. Methodological and ethical aspects of the sexual maturation assessment in adolescents. Rev Paul Pediatr. 2013;31:398-405.

40. Bowers DC, McNeil DE, Liu Y, Yasui Y, Stovall M, Gurney JG, Hudson MM, Donaldson SS, Packer RJ, Mitby PA, Kasper CE, Robison LL, Oeffinger KC. Stroke as a late treatment effect of Hodgkin's Disease: a report from the Childhood Cancer Survivor Study. J Clin Oncol. 2005;23(27):6508-15.

\section{Submit your next manuscript to BioMed Central and we will help you at every step:}

- We accept pre-submission inquiries

- Our selector tool helps you to find the most relevant journal

- We provide round the clock customer support

- Convenient online submission

- Thorough peer review

- Inclusion in PubMed and all major indexing services

- Maximum visibility for your research

Submit your manuscript at www.biomedcentral.com/submit
Biomed Central 